\title{
Application Test of Anti-Interference Electrical Method Instrument to Urban Geophysical Prospecting in Tongzhou, Beijing
}

\author{
Yonghui Su1,2, Songwei Guo 1,3, Dawei $\mathrm{Li}^{3}$, Yang Liu ${ }^{4}$ \\ ${ }^{1}$ School of Earth Sciences and Resources, China University of Geosciences (Beijing), Beijing, China \\ ${ }^{2}$ Inner Mongolia No.1 Geological Mineral Exploration and Development Co., Ltd., Hohhot, Inner Mongolia, China \\ ${ }^{3}$ Beijing Explo-Tech Engineering Co., Ltd., Beijing, China \\ ${ }^{4}$ Erdaojiang Branch of Tonghua Land and Resources Bureau, Tonghua, Jilin Province, China \\ Email: syh200@qq.com
}

How to cite this paper: Su, Y.H., Guo, S.W., Li, D.W. and Liu, Y. (2021) Application Test of Anti-Interference Electrical Method Instrument to Urban Geophysical Prospecting in Tongzhou, Beijing. International Journal of Geosciences, 12, 418-430. https://doi.org/10.4236/ijg.2021.124022

Received: March 18, 2021

Accepted: April 27, 2021

Published: April 30, 2021

Copyright $\odot 2021$ by author(s) and Scientific Research Publishing Inc. This work is licensed under the Creative Commons Attribution International License (CC BY 4.0).

http://creativecommons.org/licenses/by/4.0/

\begin{abstract}
With the rapid development of the city, it is necessary to obtain geological information within 500 meters. Electrical prospecting is not only low cost and simple operation, but also solves the problem of insufficient drilling density in a survey. However, due to the dense urban buildings and strong electromagnetic interference, it is difficult for traditional electrical instruments to obtain effective data. An anti-interference electrical method instrument is designed. In the application test of Tongzhou core area in Beijing, the resistivity sounding data collected by anti-interference electrical method instrument is stable and reliable; inversion results of sounding are basically consistent with borehole data; the known Zhangjiawan fault and Yaoxinzhuang fault are obvious; basement karst collapse area inferred is basically coincident with the historical collapse area. It is proved that the anti-interference electrical method instrument is effective and can be applied to the geological survey of underground space in other cities.
\end{abstract}

\section{Keywords}

Inversion of Minimum Layers Newton Variable Method, Vertical Projection Algorithm, Zhangjiawan Fault, Yaoxinzhuang Fault, Karst Collapse

\section{Introduction}

The anti-interference coding electrical method instrument is improved from the traditional electrical method instrument by Beijing Explo-Tech Engineering Co., Ltd. The purpose is to solve the problem of electromagnetic interference and improve the quality of data acquisition. The basic idea is to transmit pseudo-random coded pulse signal to the underground, suppress interference by using correlation 
superposition technology, realize weak signal detection and parameter extraction, and use oversampling technology to reduce the quantization noise of the system, so as to obtain the acquisition data with extremely high signal-to-noise ratio [1].

Anti-interference electrical method prospecting follows the well-established theory and construction method of the VES (Vertical Electrical Sounding) [2] [3] [4], so it is easy to be popularized and applied. In the application of urban exploration, Ge Zhiguang provided reliable basic geological data for a new urban area [5]. In addition, good results have been achieved in the exploration of mining areas and ore concentration areas with strong electromagnetic interference. For example, Wang Hongbo and others collected reliable polarizability data in the graphitized area of Inner Mongolia, which made up for the data gap in this area [6]; Nian Xingping have obtained a large number of electrical anomalies in the keketale lead zinc-mining area of Xinjiang, which provided an important basic data for comprehensive prospecting [7]. This paper introduces comprehensively the application test in the geophysical electrical prospecting of Tongzhou core area in Beijing, which obtained the electrical parameters of the stratum within 500 meters underground, verifies the known Zhangjiawan fault and Yaoxinzhuang fault, infers the scope of karst collapse area, and provides an important reference for the future urban construction.

\section{Construction Method}

Common VES configuration includes pole-dipole, double-dipole, schlumberger and so on. In the application test of Tongzhou, I used schlumberger configuration with $\mathrm{AB} / \mathrm{MN}=5$. The design and construction polar distance is shown in Table 1. The survey grid was designed to be $500 \times 500 \mathrm{~m}$. However, due to the construction difficulties caused by buildings in the city, we can only use the green belts on both sides of roads and open space of parks as much as possible to design survey line and point, and properly adjust electrode spacing. The working layout is shown in Figure 1.

\section{General Situation of Geology and Geophysics of Tongzhou, Beijing}

\subsection{General Situation of Geology}

The test area is located in the north of Tongzhou, Beijing, and its tectonic position locates in the Huangcun overlapping salient (Grade IV) in Daxing overlapping uplift area (Grade III) of Huabei fault depression zone (Grade II) [8] [9] [10]. Huangcun iterated salient extends along NE direction. The bedrock is buried deep in the southwest and shallow in the northeast, which is about $300-350$ $\mathrm{m}$. Its central part, Daxing-Tuanhe area, is the shallowest, less than $100 \mathrm{~m}$. There are faults in the test area, and the thickness of the overburden varies from

Table 1. AB/2 of Anti-interference electrical method sounding.

\begin{tabular}{llllllllllll}
\hline $\mathrm{AB} / 2(\mathrm{~m})$ & 40 & 100 & 160 & 220 & 300 & 380 & 460 & 560 & 680 & 820 & 1000 \\
\hline
\end{tabular}




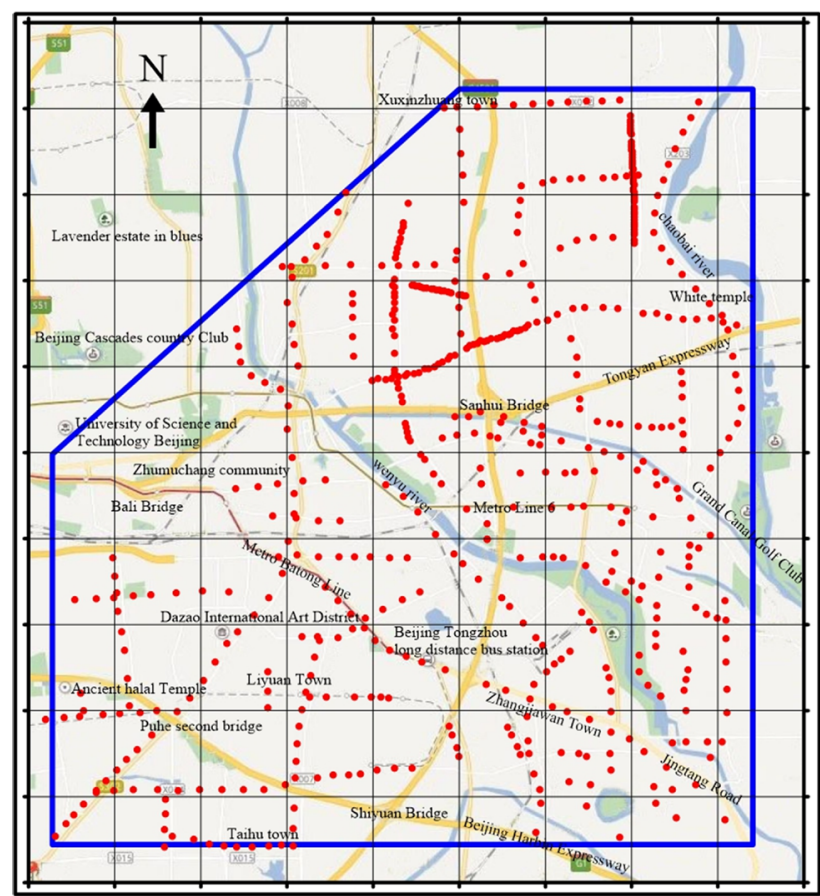

(a) Location map

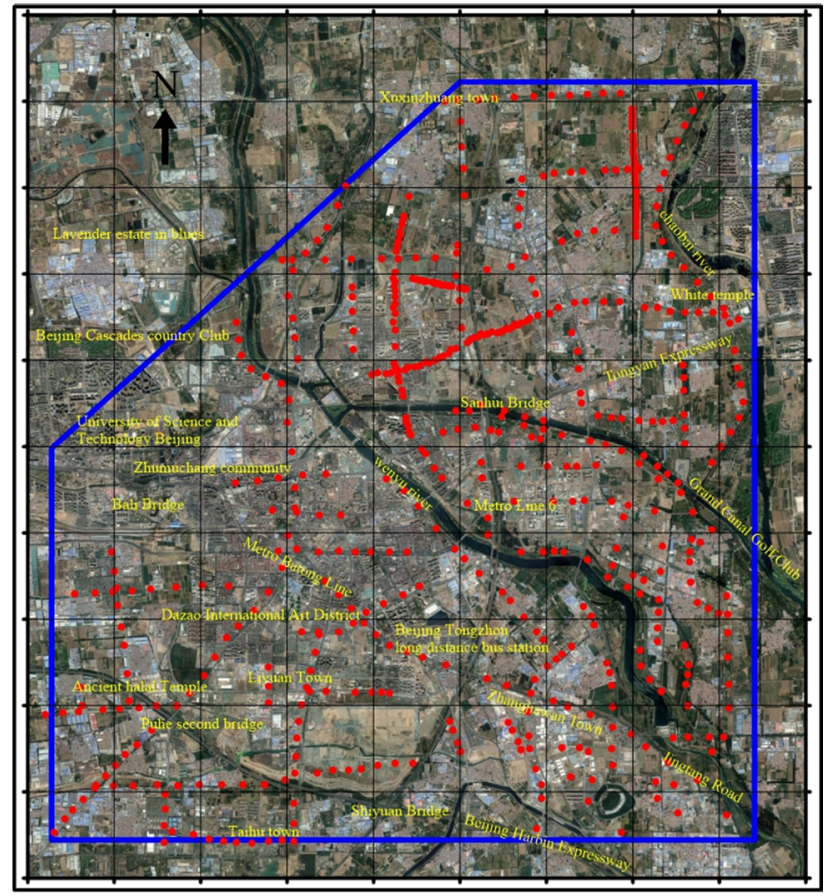

(b) Satellite image

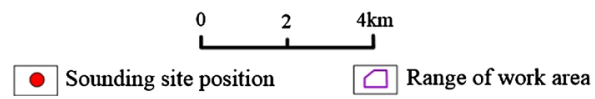

Figure 1. layout map of work area.

200 to $500 \mathrm{~m}$.

1) Strata

The bedrock strata in the test area are mainly Jixian, Qingbaikou and Cambrian. Among them, Jixian strata are mainly composed of dolomite, which is more than $2000 \mathrm{~m}$ thick, with well-developed karst fissure and water-abundance. The main lithology of Qingbaikou is sandstone, mudstone and shale, which apparent thickness is about $500 \mathrm{~m}$. Cambrian is mainly limestone, and its thickness varies greatly. In some areas, the top surface is denuded, the stratum is incomplete, and the thickness is generally less than $500 \mathrm{~m}$. The overburden includes Neogene $(\mathrm{N})$ and Quaternary (Q). The lithology of Neogene $(\mathrm{N})$ is purplish red, offwhite and gray green sandy mudstone, siltstone and conglomerate in continental sedimentary lake basin. The lithology of Quaternary (Q) revealed by drilling is composed of silt soil, silt sand, silty clay, fine sand, etc. There is a local gravel strata development, which has the unconformity with the underlying rocks. The thickness of gravel strata varies greatly, ranging from 200 to $700 \mathrm{~m}$.

2) Faults

The faults in the Beijing area are well-developed, and NE-trending and NWtrending faults converge with each other. The faults in the work area mainly include the Zhangjiawan fault and Yaoxinzhuang fault, which meet at the southeast corner of the work area. The Zhangjiawan fault is the south-eastern section of the Nankou-Sunhe fault, which runs from Xinhua to Yaoxinzhuang. The general trend of the Zhangjiawan fault is $310^{\circ}$. According to Zhang Lei, Bai Lin- 
gyan, etc. [11] [12] [13], the Nankou-Sunhe fault is a Quaternary active fault with intermittent activity characteristics. Yaoxinzhuang fault is located in the southeast corner of the work area. The Yaoxinzhuang fault is developed in the southern part of the work area in Xiji-Yongledian section of Tongzhou, Beijing. The Yaoxinzhuang fault starts from Niubaotun in the south, passes by Zhongxinzhuang, Yaoxinzhuang and Buluofa. YaoXinzhuang fault strikes NE and dips to NW. The total length of Yaoxinzhuang fault is $18 \mathrm{~km}$ and its extension is relatively short. It is the main fault in the westernmost part of the southern section of Xiadian fault zone [14]-[20]. Xiadian fault zone is an important active buried fault in the northern plain of North China Plain. Xiadian fault zone, which runs through Hebei and Beijing, is a NE striking and lithosphere-scale regional deep fault zone. The Xiadian fault zone is characterized by large fault throw, long extension, and deep cutting. Xiadian fault zone is a basin boundary fault which controls the strata and evolution of the Dachang sag, and is the boundary between the Dachang sag and the Daxing uplift. Xiadian fault zone not only has the characteristics of high dip angle and leaping to near surface [19], but also has a complex structure, which is a Quaternary active fault zone composed of a series of faults. In Xiadian fault zone, there are Yaoxinzhuang fault, Xiadian fault and Yongledian fault from west to east, and the fault throw increases successively [16].

\subsection{Geophysical Electrical Characteristics}

According to the existing data, the stratigraphic resistivity in the test area is shown in Table 2.

\section{Achievement Exhibition}

\subsection{Data Processing and Interpretation Basis}

There are two main steps in data preprocessing. First of all, we pick up and superposition the collected electrical signal data, and calculate the apparent resistivity. After that, we remove flying points from the electrical sounding curves,

Table 2. Statistical table of stratigraphic electricity.

\begin{tabular}{|c|c|c|c|c|c|c|}
\hline & stratum & & lithology & $\begin{array}{c}\text { Resistivity } \\
(\Omega \cdot \mathrm{m})\end{array}$ & $\begin{array}{l}\text { Log resistivity } \\
\quad \operatorname{Lg}(\Omega \cdot \mathrm{m})\end{array}$ & remarks \\
\hline \multirow{2}{*}{ Cenozoic } & Quaternary & Q & Silt, clay, silt, fine sand & $0-100$ & $0-2.0$ & \multirow{8}{*}{$\begin{array}{c}\text { The average of } \\
\text { resistivit-ies }\end{array}$} \\
\hline & Neogene & $\mathrm{N}$ & Mudstone, siltstone, onglomerate & $9.1-13.9$ & $0.96-1.14$ & \\
\hline \multirow{2}{*}{ Lower Paleozoic } & Ordovician & $\mathrm{O}$ & Limestone & $800-1500$ & $2.9-3.2$ & \\
\hline & Cambrian System & $\in$ & Limestone, Marl, shale & $254-608$ & $2.4-2.8$ & \\
\hline Upper Proterozoic & Qingbaikou & Qn & Sand shale intercalated with carbonate rock & $136-248$ & $2.13-2.40$ & \\
\hline \multirow{2}{*}{ Mesoproterozoic } & Jixian & $\mathrm{Jx}$ & Sand shale intercalated with carbonate rock & $540-1000$ & $2.73-3$ & \\
\hline & Changcheng & $\mathrm{Ch}$ & Dolomite, marl, shale & $>600$ & $>2.77$ & \\
\hline Archean & & $\mathrm{Ar}$ & gneiss & $>700$ & $>2.84$ & \\
\hline
\end{tabular}


and edit and smooth curves appropriately. The purpose is to avoid "false anomaly" and "false fault" so that the overall effect of the entire profile and the whole work area is not affected. Usually, inversion results of resistivity sounding are important interpretation parameters. The inference procedure should follow the basic principle from known to unknown. The known geological information can be obtained from the borehole information near the sounding point which can be used as the calibration parameter of inversion result of "borehole side sounding", in order to infer and interpret other sounding points.

Due to the influence of urban buildings in the core area of Tongzhou, Beijing, we arranged the survey points flexibly. As a result, the survey points are relatively independent from each other, and it is hard to form a complete survey line profile and calculate by 2-D inversion. In addition, geological data show that most of the working areas are located in Huangcundie uplift, with obvious strata classification which is a typical 1-D geoelectric model, so 1-D inversion algorithm was adopted. Considering the obvious electrical difference of strata and discontinuous change, we choose inversion of minimum layers Newton variable method that principle is to use Tikhonov regularization to deal with the errors, automatically inferring the minimum number of layers of the model corresponding to the resistivity sounding curve, as well as the thickness and stratigraphic electricity. Inversion results (Table 3) of single site near boreholes show that the whole test area can be divided into three major electrical layers:

1) The first layer is characterized by medium and high resistivity. Due to the influence of land surface heterogeneity, the resistivity varies greatly, ranging from 1 - $100 \Omega \cdot \mathrm{m}$ ( $\log 0$ to 2$)$. It can be inferred that the lithology is mainly loose sediments and deposits, which are basically consistent with the collected physical property data. Therefore, the first layer can correspond to the Quaternary.

2) The second layer exhibits low resistivity. The thickness of the strata does not change much, and the resistivity of the strata is $10-20 \Omega \cdot \mathrm{m}$, which is basically consistent with the collected physical property data of $9.1-13.9 \Omega \cdot \mathrm{m}$ (about $\log 1)$. The second layer can correspond to Neogene. The lithology is mainly composed of sandy conglomerate with mudstone and sandy mudstone.

3) The third layer is characterized by high resistivity obviously. The resistivity is greater than $100 \Omega \cdot \mathrm{m}(>\log 2)$. The third layer can be inferred as basement limestone, and the lithology is mainly limestone and carbonate. The third layer corresponds to Ordovician, Cambrian, Qingbaikou, Jixian and other basement stratum.

In short, there are obvious electrical differences of stratum in the test area. Most of the basement show obvious high resistivity characteristics. The sounding curve is mainly $\mathrm{G}, \mathrm{H}, \mathrm{KH}$ type. The thickness and resistivity of statum can be acquired through 1-D inversion results, thickness of stratum can be used to calculate and infer the range of stratum depth, and the stratigraphic resistivity can be used to infer the main lithology of stratum. In addition, boreholes are used to constrain the inversion of nearby electrical sounding points and to calibrate the 
horizons (Figure 2, Table 3), which effectively reduces the multiplicity of inversion. It is worth noting that the inversion results of some survey points show obvious low-resistivity anomalous body and large basement depth. It is speculated that the above situation is related to the development of karst.

\subsection{Inference of Stratum}

Based on the obvious differences of stratigraphic resistivity, we used the consistency of electrical layering and geological stratification to perform point-by-point inversion on each sounding point. We obtained the resistivity and thickness of stratum of each sounding point, and drew the buried depth contour map of
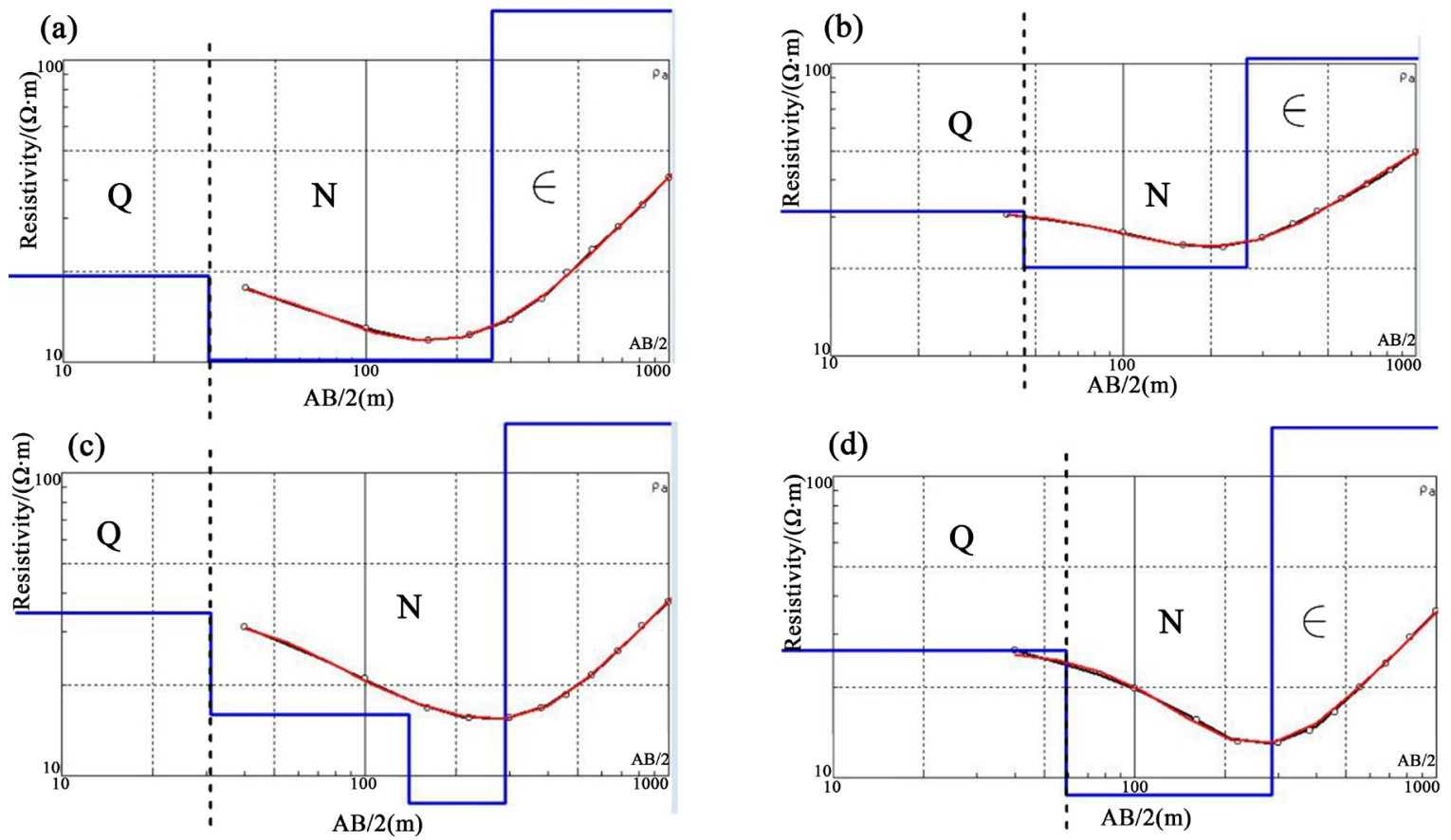

Sounding curve near borehole
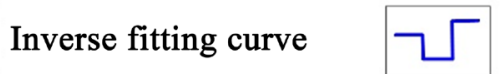

Inversion model

Figure 2. Inversion result curves of single site near boreholes.

Table 3. Inversion results of Anti-interference electrical method sounding near boreholes.

\begin{tabular}{ccccccc}
\hline No. & $\begin{array}{c}\text { Borehole } \\
\text { name }\end{array}$ & $\begin{array}{c}\text { Depth of bedrock } \\
\text { exposed by drillin(m) }\end{array}$ & $\begin{array}{c}\text { Drilling reveals } \\
\text { bedrock strata (lithology) }\end{array}$ & $\begin{array}{c}\text { Site No. of electrical } \\
\text { sounding near borehole }\end{array}$ & $\begin{array}{c}\text { Inversion of } \\
\text { bedrock depth (m) }\end{array}$ & $\begin{array}{c}\text { Inversion of bedrock } \\
\text { resistivity }(\Omega \cdot \mathbf{m})\end{array}$ \\
\hline 1 & T001 & 374 & $\in$ (Limestone) & 170 & 367 & 162 \\
2 & TJ-7 & 326 & $\in$ (Limestone) & 448 & 338 & 305 \\
3 & TJ-5 & 313 & $\in$ (Limestone) & $445 / 251$ & $214 / 265$ & $52 / 85$ \\
4 & TJ-1 & 276 & $\in$ (Limestone) & 250 & 265 & 104 \\
5 & $151-70$ & 295 & $\in$ (Limestone) & 395 & 289 & 2274 \\
6 & Tg-2 & 298 & $\in$ (Limestone) & 410 & 273 & 167 \\
7 & $151-71$ & 311 & $\in$ (Limestone) & 401 & 337 & 98 \\
\hline
\end{tabular}


inference Quaternary strata corresponding to the depth of the first layer (Figure 3(a)) and contour map of inference basement corresponding to the depth of the third layer (Figure 4(a)). The test area is generally stable in formation thickness. The stratum resistivity varies greatly locally and shows low-resistivity anomaly. We infered that there may be related to karst collapse and deserves attention. We didn't detect a high-resistivity basement in the southeast corner of the test area, indicating that the stratum is thick in this area and the rift features are obvious.

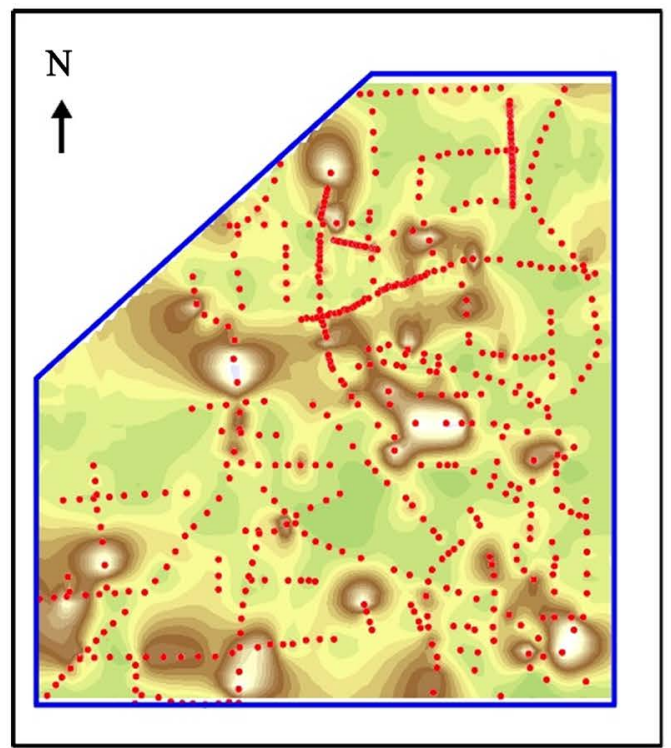

(a) Depth

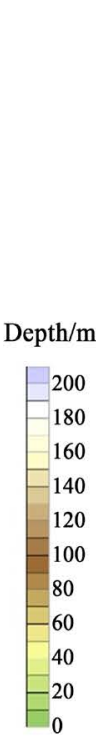

$\begin{array}{lll}0 & 2 & 4 \\ 1\end{array}$

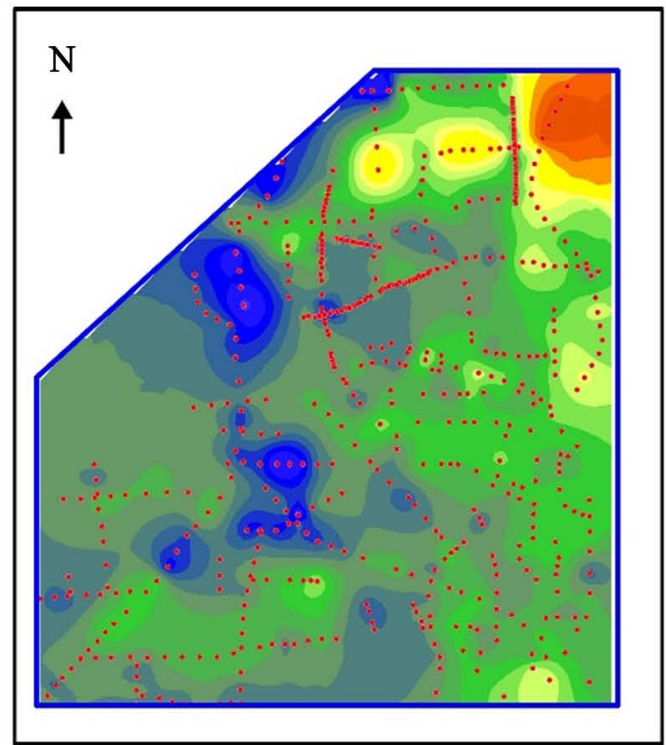

(b) Resistivity

Figure 3. Contour map of inference quaternary strata.

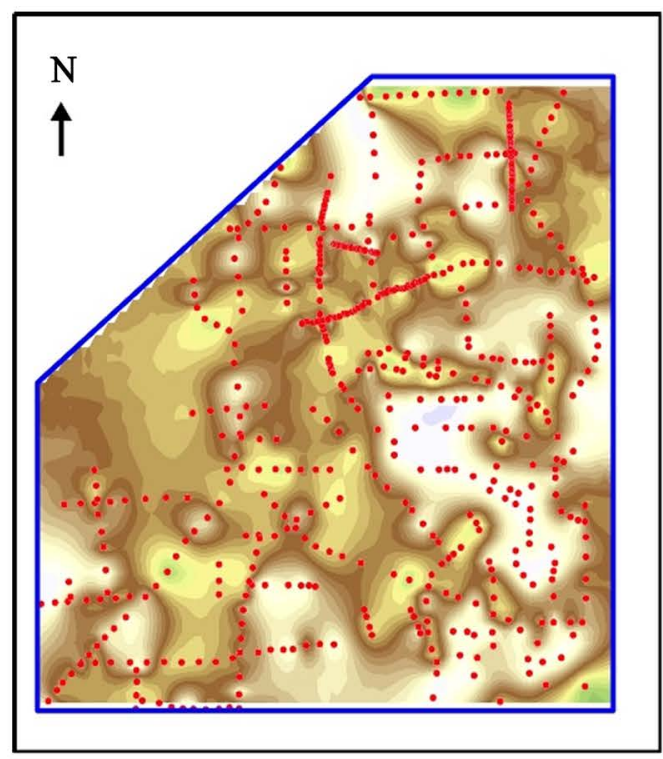

(a) Depth

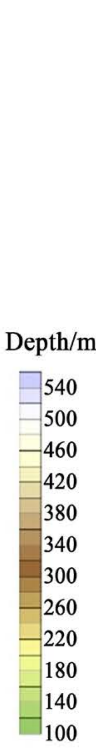

$0 \quad 2 \quad 4 \mathrm{~km}$

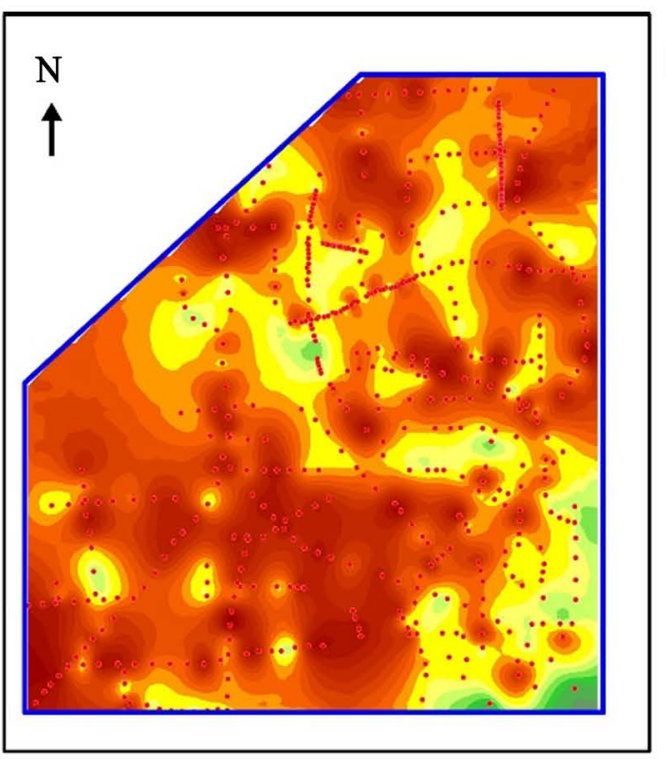

$\square$ Site Position
$\square$ Work area zone

(b) Resistivity
Resistivity $\lg (\Omega \cdot \mathrm{m})$

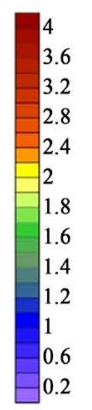

Resistivity $\lg (\Omega \cdot \mathrm{m})$

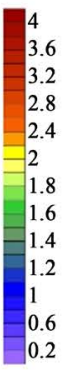

- Site Position
$\square$ Work area zone

Figure 4. Contour map of inference basement. 


\subsection{Verification of Known Faults}

The electrical characteristics of the deposited stratum generally show uniformity or little change in the horizontal direction. The structural deformation may cause corresponding stagger of the electrical layer. The resistivity contour map shows the resistivity gradient zone or the increased contour density, and the shape is consistent with the structural characteristics. The data shows that the main faults in the test area are Zhangjiawan fault and Yaoxinzhuang fault. The Zhangjiawan fault, numbered F1 in Figure 5, belongs to the south-eastern section of the Nankou-Sunhe fault, which is located near Xinhua to Yaoxinzhuang. Yaoxinzhuang fault, numbered F2 in Figure 5, is located in the southeast corner of the test area and is only part of itself.

1) Zhangjiawan Fault

Zhangjiawan fault shows obvious resistivity gradient belt (Figure 6), and it strikes NW. The location of the Zhangjiawan fault is basically consistent with the geological data. The depth of Zhangjiawan fault is obvious within 300 meters, but not below 300 meters. This is basically consistent with the viewpoint that the Nankou-Sunhe fault belt is a Quaternary active fault [11] [12] [13]. From the view of position, Zhangjiawan fault corresponds to Wenyu River in Tongzhou.

2) Yaoxinzhuang Fault

Yaoxinzhuang fault also shows obvious linear distribution, with obvious jump features of electrical change. It is inferred that Yaoxinzhuang fault strikes NE and dips to SE. Yaoxinzhuang fault is similar to Xiadian fault, which is characterized by high dip angle and discontinuous to near surface. Resistivity contour maps view at different depths also verifies this feature. Due to the limitation of electrical sounding, we can't detect the basement.

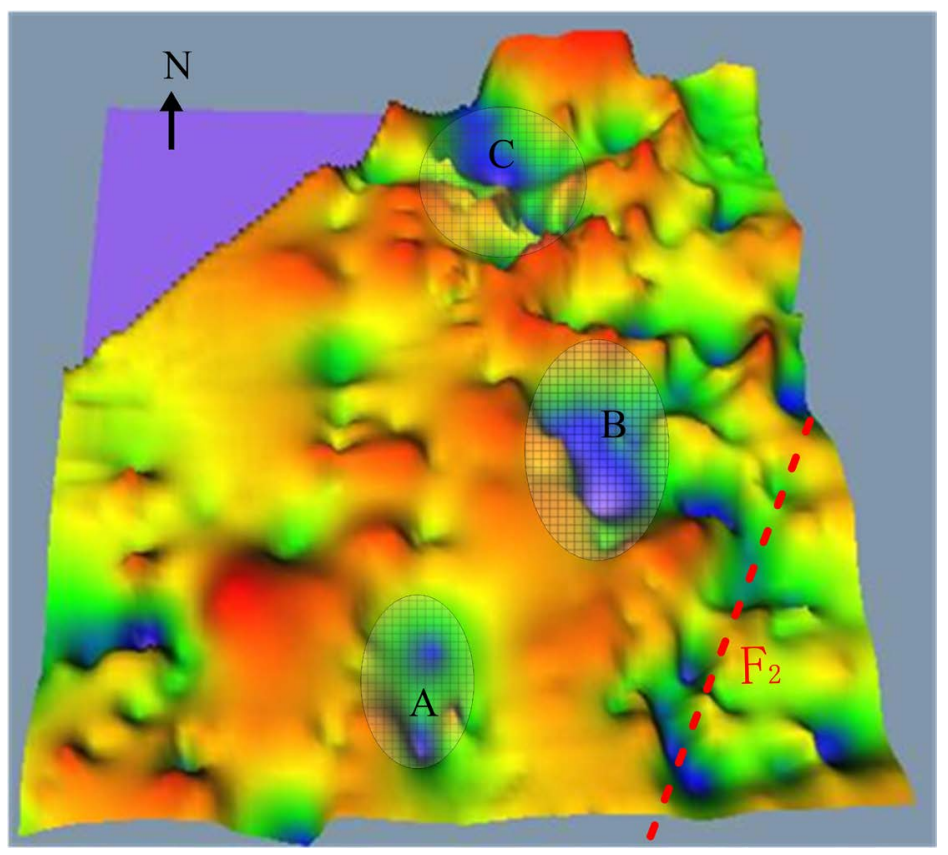

Figure 5. Three-dimensional sketch of basement undulation. 


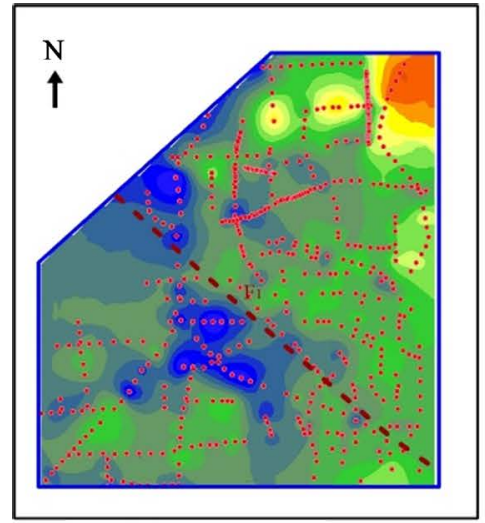

(a) Depth $=30 \mathrm{~m}$

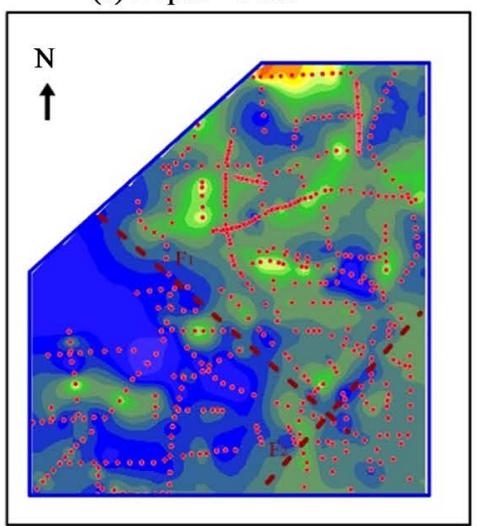

(d) Depth $=150 \mathrm{~m}$

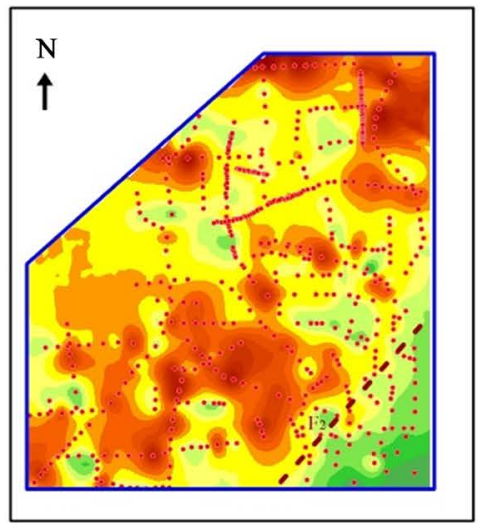

(g) Depth $=300 \mathrm{~m}$

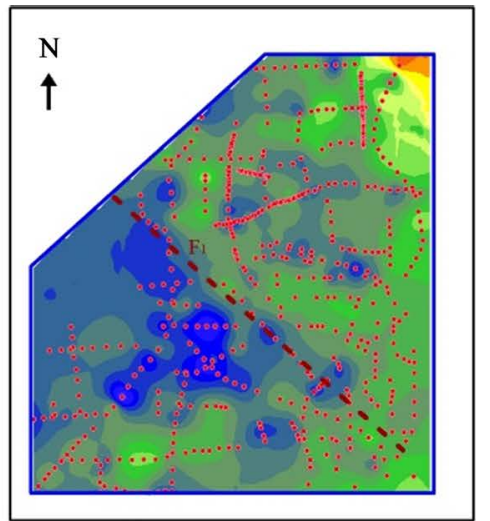

(b) Depth $=50 \mathrm{~m}$

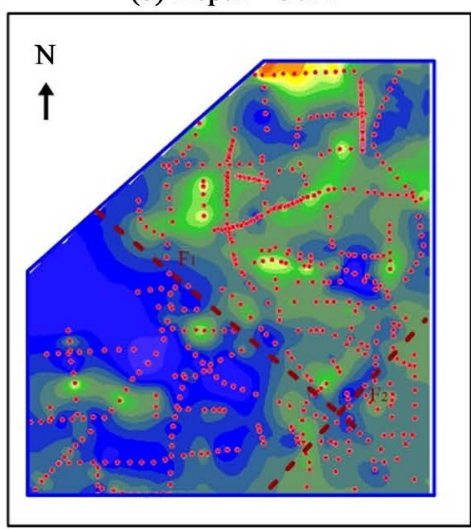

(e) Depth $=200 \mathrm{~m}$

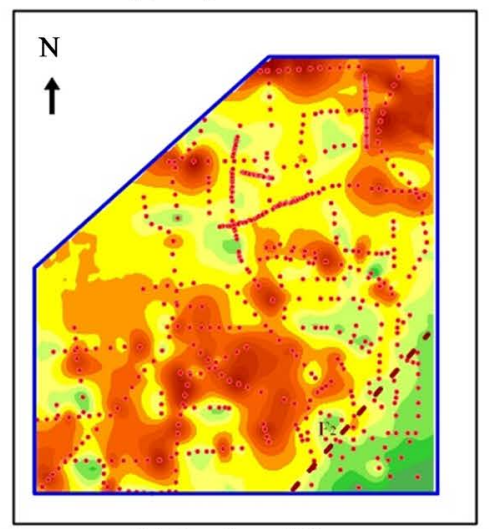

(h) Depth $=400 \mathrm{~m}$

$0 \quad 2 \quad 4 \mathrm{~km}$

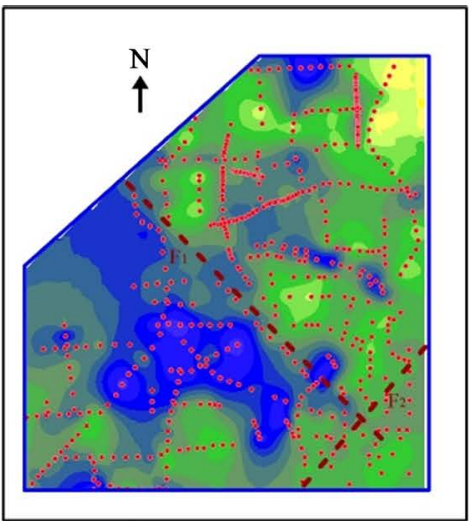

(c) Depth $=100 \mathrm{~m}$

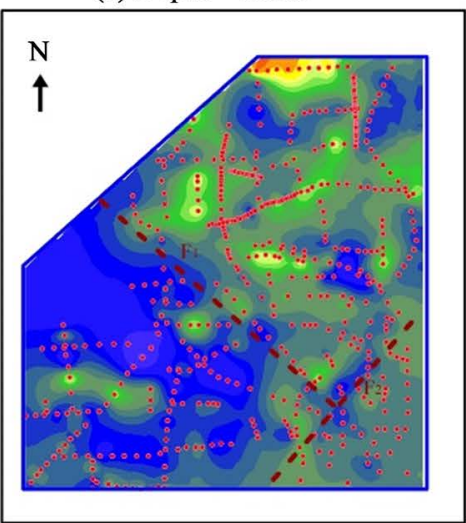

(f) Depth $=250 \mathrm{~m}$

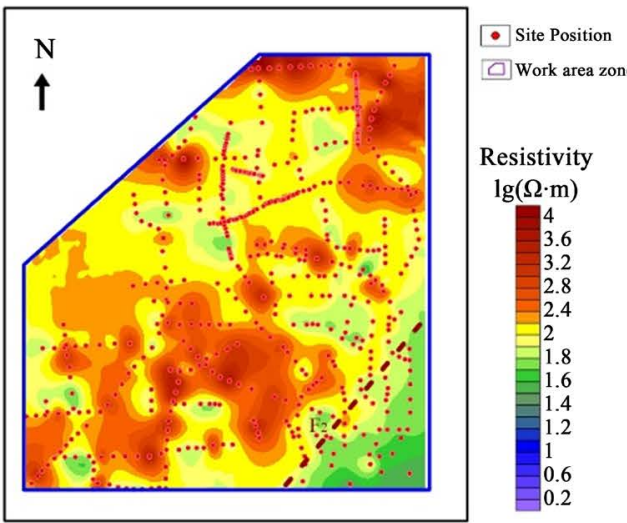

(i) Depth $=500 \mathrm{~m}$

Figure 6. Inversion concour map of different depths.

\subsection{Inference of Basement Karst Development}

In addition, through the change characteristics of basement resistivity and depth, we can speculate the development of buried karst which Tongzhou, Beijing belongs to. If the basement limestone does not contain water, the rock with less porosity and high resistivity is denser. On the contrary, if the basement limestone has a high water content, the rock structure is loose and the porosity is large, so it shows low-resistivity anomaly. The contour maps of inference basement and the inversion concour maps of depths of 300, 400, and $500 \mathrm{~m}$ (Figures 
6(g)-(i)) show three obvious low-resistivity anomalous bodies. Anomalies have certain continuity, and are mostly located near the structure. In particular, the junction between Zhangjiawan fault and Yaoxinzhuang fault presents an obvious low-resistivity anomaly. The data shows that [11] [16] the above faults are all Quaternary faults, and the location roughly coincides with the historical collapse area. It is inferred a high incidence area of geological disasters, which is worthy attention.

\subsection{Redrawing the Sounding Profile by Vertical Projection Algorithm}

The survey point designed usually cannot be carried out at the designed position in actual electrical prospecting and construction, because the designed survey point is affected by various factors, and construction cannot be carried out at the survey point. There is a certain deviation between the actual survey point and the survey line. These problems are particularly obvious in the geophysical prospecting in the core area of Tongzhou. The test area is densely covered with houses and buildings (Figure 1), and the survey points and electrode spacing can only be arranged on roads and trails. It is difficult to form a complete straight survey line. In order to obtain a better geological interpretation, the profile should be perpendicular to the stratigraphic boundary or structural trend. Therefore, vertical projection method is proposed to redraw the profile. By selecting the first and last survey points of the profile in the contour map, and setting the projection range to $100 \mathrm{~m}$, then the survey points data smaller than the projection range can be projected onto the profile through the above method because of 1-D inversion and relatively independent of all survey points. In this way, the inversion result of the survey point data near the profile can be used to realize the reconstruction of the inversion profile.

Setting the projection range to 100 meters is to fit the actual situation as far as possible, so as not only to ensure that projection points is as many as possible, but also to exclude the measurement points that are too far from the projection line. According to the vertical fault strike, we made the projection profile Profile 1 for the Zhangjiawan fault F1, as shown in Figure 7. And we made the projection profile Profile 2 for the Yaoxinzhuang fault F2, as shown in Figure 8.

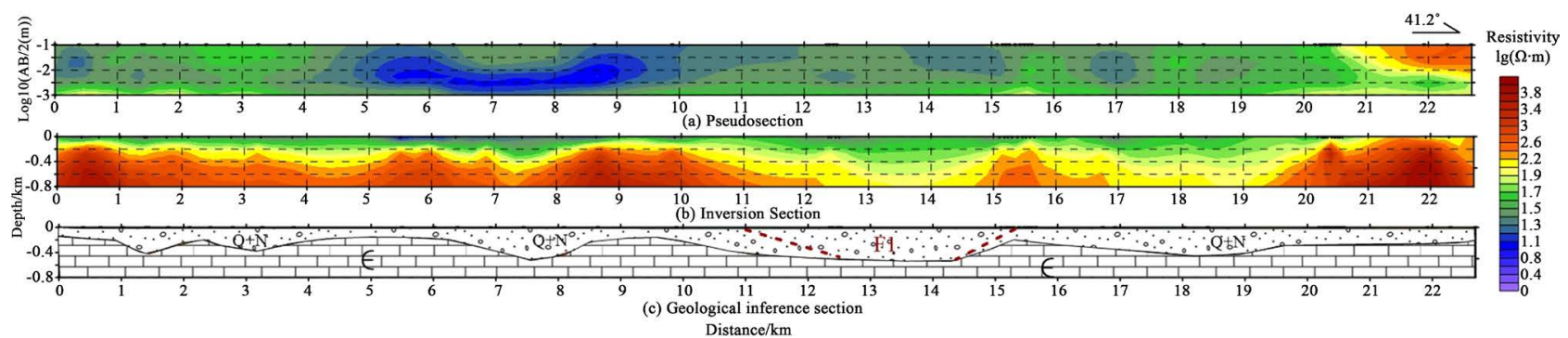

Figure 7. Comprehensive projection profile of Profile 1. (a) Pseudo-cross-section; (b) inversion cross-section; (c) geological inference map. 


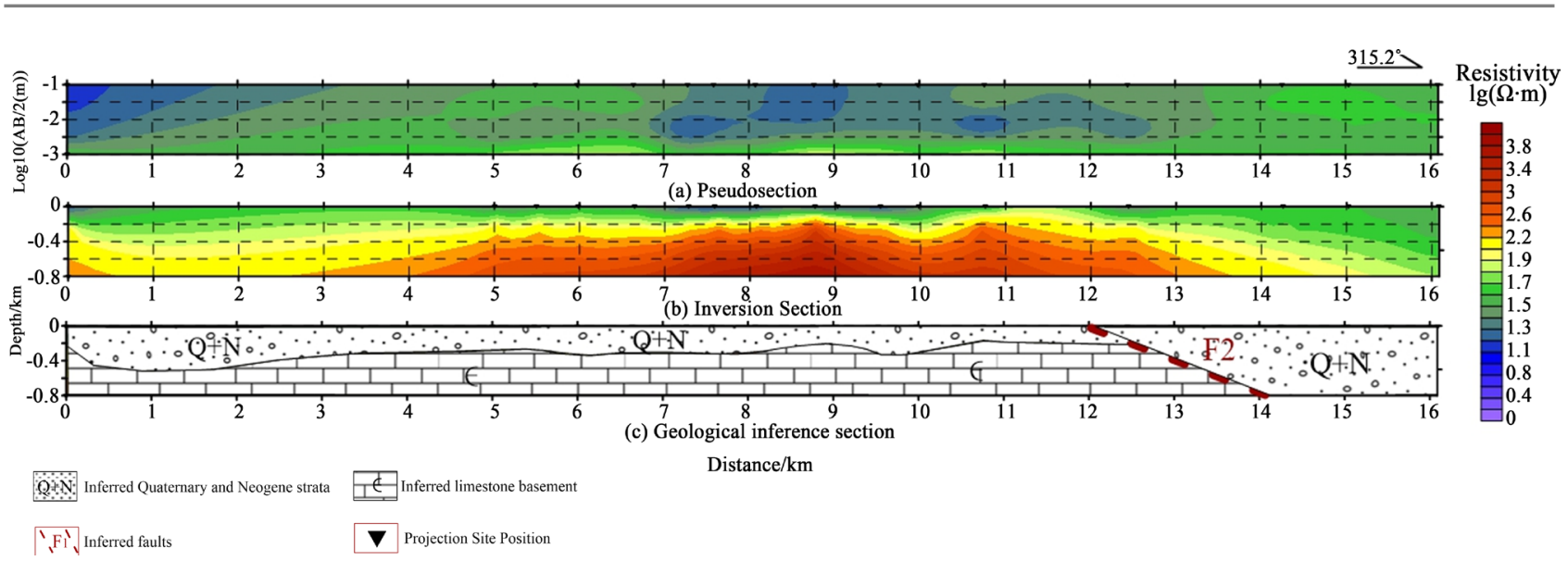

Figure 8. Comprehensive projection profile of Profile 2. (a) Pseudo-cross-section; (b) inversion cross-section; (c) geological inference map.

\section{Conclusions}

1) Anti-interference electrical method prospecting updated traditional electrical prospecting by using completely the same construction way, as the data collected by anti-interference electrical method instrument is stable and reliable. It can provide a supplement for the application of geophysical electrical prospecting in areas with strong electromagnetic interference such as cities, mining areas.

2) In the application test of the core area of Tongzhou, Beijing, the boreholes data is used to constrain the resistivity sounding inversion that shows the basement of most of the test area is buried at a depth of about $300 \mathrm{~m}$, corresponding to the Huangcun protrusion, and the cover layer infers the Quaternary strata and the Neogene strata respectively. Both the Zhangjiawan fault struck NW and the Yaoxinzhuang fault struck NE present clearly. Many low-resistivity anomalies near the faults, whose inversion depth is about $500 \mathrm{~m}$, may be related to karst collapse. Three basement low-resistivity anomaly areas are defined, which roughly coincide with the historical karst collapse area where are inferred to be high-risk areas of geological disasters, and deserve attention.

In short, the application test effect of the anti-interference electricity method prospecting in the core area of Tongzhou, Beijing is good. The extrapolation of stratum thickness, lithology and faults are basically consistent with geological data. It makes up for the shortcomings of insufficient drilling density, and proves the feasibility and effectiveness of the anti-interference electrical method instrument. As a geophysical electrical prospecting method for urban underground space geological exploration, this instrument has a certain value in popularization and application.

\section{Conflicts of Interest}

The authors declare no conflicts of interest regarding the publication of this paper. 


\section{References}

[1] Luo, X.Z., Li, D.W., Peng, F.P., et al. (2014) Implementation and Applications of an Coded Electrical Instrument with Anti-Interference Ability. Progress in Geophysics, 29, 944-951. (In Chinese)

[2] Wu, B., Li, S.J., Liang, Y.Q., et al. (2019) Study on Geophysical Method of Urban Underground Space Exploration in Chengdu. Acta Geologica Sichuan, 39, 194-202+224.

[3] Hu, X.P., Cui, Y.J., Dong, J., et al. (2012) Application of Direct Current Mothod in Underground Water Survey in Mountain Area. Science Technology and Engineering, 12, 4258-4260+4270.

[4] Zhang, G., Tuo, X.G., Liu, Y., et al. (2013) The Application of Electrical Sounding Method in Seeking the Groundwater of a Part of Wuding River. Science Technology and Engineering, 13, 7953-7959.

[5] Ge, Z.G., Chen, Y.S. and Fu, F.H. (2017) Application of Anti-Interference Electric Instrument to Detection of Fault in Strong Electromagnetic Interference Environment. Chinese Journal of Engineering Geophysics, 14, 541-545.

[6] Wang, H.b. (2018) Application of KGR-1B Anti-Jamming Electro-Detecting in Graphite Ore Deposit. Coal and Chemical Industry, 41, 79-82.

[7] Nian, X.p. (2019) Application of Anti Interference Electrical Method in Keketale lead Zinc Mining Area. Xinjiang Nonferrous Metals, 42, 77-78.

[8] Geological Publishing House (1991) Beijing Geology and Mine Bureau. Regional Geology of Beijing Municipality, 449-457.

[9] Li, Q.L., Lei, X.D. and Li, C. (2018) Application of a Coded Electrical Method with Anti-Interference Ability to Detect Geological Structures in Tongzhou Karst Areas. Geotechnical Investigation and Surveying, 46, 71-78.

[10] He, Y., Lei, X.D., Guan, W., et al. (2018) Spatial Distribution Characteristics of Yanjiao Fault in Beijing Sub-Central Area. Geophysical and Geochemical Exploration, 43, 461-467.

[11] Bai, L.Y., Li, X., Qin, H.M., et al. (2018) Study on the Cyclic Stratigraphy Activity of Nankou-Sunhe Fault in Beijing Plain since Quaternary and Its Tectonic Significance. Geoscience, 32, 270-278.

[12] Zhang, L., Bai, L.Y., Zhao, Y., et al. (2017) The Difference of Deposition Rate in the Boreholes at the Junction between Nankou-Sunhe Fault and Huangzhuang-Gaoliying Fault and Its Response to Fault Activity in the Beijing Area. Seismology and Geology, 39, 1048-1065.

[13] Zhang, L., Wang, J.M. and Zhang, X.L. (2017) The Study of Neotectonic Movement in Beijing Plain Area. Urban Geology, 12, 6-15.

[14] Meng, L.P., Peng, Y.Q., Ran, Z.J., et al. (2019) Feature of Southwest Segment of Xiandian Fault Revealed through Shallow Seismic Prospecting. China Earthquake Engineering Journal, 41, 155-161.

[15] Zhang, J.P., Yuan, L.J. (2018) Influence of Xiadian Fault on Geothermal Resource Distribution-A Case Study in Xiji Area, Tongzhou District, Beijing. Urban Geology, 13, 15-20.

[16] He, F.B., Bai, L.Y., Wang, J.M., et al. (2013) Deep Structure and Quaternary Activities of the Xiadian Fault Zone. Seismology and Geology, 35, 490-505.

[17] Deng, M., Shen, J., Li, X., et al. (2018) Analysis of Paleoseismic Events of the Dahuzhuang Trench at the Xiadian Fault. Journal of Seismological Research, 41, $293-301+344$. 
[18] Chen, Y.Y., Shen, J., Zhang, J.G., et al. (2017) Grain-Size Analysis Sedimentary Environment Research of Quaternary Sediments Ong Xiadian Active Fault. Journal of Institute of Disaster Prevention, 19, 17-27.

[19] Zhao, C.B., Feng, S.Y., Qin, X.Y., et al. (2010) Research on the Shallow Structure Characteristics of Xiadian Fault Using High-Resolution Artificial Seismic Exploration Method. Journal of Seismological Research, 33, 81-85+119.

[20] Ran, Z.J., Li, H., Lv, G.J., et al. (2013) Seismic Detecting for the Shallow Tectonic Feature of the Xiadian Fault. China Earthquake Engineering Journal, 35, 656-663. 